\title{
The Effectiveness of Lower Back Massage on Reducing Labor Pain for Primiparous at Maternity and Children's Hospital
}

\author{
Rawah Siraj Iskandar ${ }^{*}$, Ahlam E. Al-Zahrani² and Jilan A. Al-Battawi ${ }^{3}$ \\ ${ }^{1}$ Master student KAU, Nursing director in Kulais Hospital, \\ Saudi Arabia. \\ ${ }^{2}$ Assistant Professor, Women Health Nursing King Abdulaziz \\ University Jeddah, Saudi Arabia. \\ ${ }^{3}$ Associate Professor, Obstetrics and Gynecology Nursing King \\ "Correspondence: \\ Rawah Siraj Iskandar, Master student KAU, Nursing director in \\ Kulais Hospital, Saudi Arabia, E-mail: iskandar@hotmail.co.uk. \\ Received: 19 may 2018; Accepted: 01 June 2018 \\ Abdulaziz University Jeddah, Saudi Arabia. \\ Citation: Rawah Siraj Iskandar, Ahlam E. Al-Zahrani, Jilan A. Al-Battawi. The Effectiveness of Lower Back Massage on Reducing \\ Labor Pain for Primiparous at Maternity and Children's Hospital. Nur Primary Care. 2018; 2(3): 1-4.
}

\begin{abstract}
Background: Massage therapy is a non-pharmacological method for reducing labor pain, usually used during the first stage of labor.

Aim: To assess the effectiveness of lower back massage on reducing labor pain for primiparous.

Methods: A quantitative, Randomized Controlled Trial (RCT) design was used to carry out the study.

Tool: one tool was used. It was divided into four parts: Part I: It assesses the mothers' demographic, and current labor data. Part II: It assesses the pain intensity before applying the intervention by visual analogue scale (VAS). As well, it assesses the mothers' expression during labor. Part III: It assesses the pain intensity after 30 minutes of implementing the intervention by VAS. As well, it assesses the mothers' expression during labor. Then, it evaluates the mothers 'satisfaction from intervention by using Likert Scale. Part IV: Partogragh sheet for mothers' assessment.

Subjects: The researcher was used a purposive sampling which selected related to some included criteria. The sample consisted of 60 mothers in the first stage of labor divided into two groups; experimental (30 mothers) and control group (30 mothers).
\end{abstract}

Setting: This study carried out in Maternity and Children's Hospital (MCH) in Jeddah, Saudi Arabia.

Results: The study results showed that experimental group had lower pain intensity at $4 \mathrm{~cm}$ and $6 \mathrm{~cm}(p<0.05)$ in comparison with control group, but at $8 \mathrm{~cm}$ no significant difference found between both groups ( $p>0.05)$. In addition mothers in experimental group were more satisfied in comparison with control group.

Conclusion: A lower back massage is an effective, non-invasive and alternative intervention, to reduce labor pain and increase the level of mothers' satisfaction.

\section{Keywords}

Childbirth, Counter pressure, Labor pain, Lower back massage, Non-pharmacological methods, Pain relief, Primiparous.

\section{Introduction}

Labor pain is one of the most severe pains in a mother's life. It is affected by multiple factors, including psychological, physiological, and biochemical factors, and appreciation of labor pain severity differs. Infrequently, some mothers can be tolerated this pain, whereas others have described it as the worst experience in life. Primiparous mothers experience more pain than multiparous. Psychosocially, many factors influence a mother's experience of labor pain, such as fear and anxiety, ethnicity, and education. For example, mothers may experience less pain during 
spontaneous labor than induced labor [1].

Labor pain initiates from different sites during the stages of labor and delivery process. In the first stage of labor, pain occurs through contractions. It is originated in the uterus and cervix by the distension of uterine tissues and dilation of the cervix. Labor pain can be referred to the abdominal wall, lumbosacral region, iliac crests, gluteal areas, and thighs [2].

Pain management during delivery represents an important challenge for both health care specialists and laboring mothers. Pain management includes pharmacological and non-pharmacological methods. Pharmacological methods, such as epidural analgesia, have been confirmed to be effective in reducing pain during labor, but they have many risks, like low blood pressure, motor blocks, hindering leg movement, urinary retention, and fever [3]. Non-pharmacological methods, such as relaxation techniques, are often safe, simple, and inexpensive. In addition, they can be used throughout childbirth, and the mothers have a sense of control over their labor, decreasing the need for obstetric interventions. Several studies and systematic reviews have recommended the use of non-pharmacological methods for pain management, either as a primary method or as a complement to pharmacological methods [3].

Lower back massage is classified as one of the effective nonpharmacological interventions to reduce labor pains. Lower back massage acts as an experience of comfort and pleasure to the mother. In labor, massage brings mother closer to the person who's caring for her. Touch can make mother feel better while her coping with contractions and perhaps tired or frightened. There are certain positions for labor that help to make massage easier. For example, leaning forward on a birth ball or sitting on a chair turned back to front, will make it easier for nurse to put steady pressure on mother lower back. Massage may ease pain in the first stage of labor. It may help mother to cope with her contractions by making her feel less intense and more manageable [4].

When the mother experiences pain and discomfort during labor, it can lead to many complications. Anxiety is one of the most significant factors causing mostly primiparous mothers to be involved in elective cesarean section $(\mathrm{C} / \mathrm{S})$. The severity of this anxiety depends on many factors, such as personality, knowledge, and culture. There are many interventions related to understanding the physiological and psychological processes that underlie the experience of pain that nurses and midwives can implement to help reduce anxiety and promote comfort [5].

Nurses and midwives being conversant about the plans for managing labor pain allows the laboring mothers to make decisions about the various pain management methods they can use [6]. Nurses and midwives are the health care professionals who provide the most health care services for mothers during labor. They provide expert special care during labor, delivery, and after birth. They also provide high-quality antenatal and postnatal care to promote the mother's health during and after pregnancy, as well as identify problems early and conduct any complications [7]. The aim of this study is to assess the effectiveness of lower back massage on reducing labor pain for primiparous at Maternity and Children's Hospital.

\section{Materials and Methods}

Study design

In this study, the researcher used a quantitative, Randomized Controlled Trial (RCT) to answer the research questions.

\section{Study setting}

The study was conducted in Labor and Delivery Unit at $\mathrm{MCH}$ in Jeddah, Saudi Arabia.

Sample

In this study, a purposive sampling was used; 60 primiparous mothers were divided into two groups, experimental and control, based on specific characteristics with preference for the inclusion criteria of selection.

\section{Inclusion criteria}

The inclusion criteria for selecting the mothers were as follows: (a) mothers must be primiparous and normal labor, (b) between 37 and 41 gestational weeks, and (c) in the first stage of labor, and must (d) participate voluntarily and (e) consent to lower back massage at least three times during the first stage of labor.

\section{Study tool}

In this study structured questionnaire has been used to assess the effectiveness of lower back massage for mothers during the first stage of labor. The questionnaire consisted of four parts which were all used with the experimental and control groups. Part I assessed the mothers' sociodemographic data and current labor data. Part II aimed to assess the mothers' pain intensity before applying the intervention at $4 \mathrm{~cm}, 6 \mathrm{~cm}$, and $8 \mathrm{~cm}$ cervical dilatations by VAS. The researcher assessed the intensity of pain during the first stage of labor by VAS. Also assessed the mothers' expressions during labor. Part III aimed to assess the pain intensity after 30 minutes of implementing the intervention at $4 \mathrm{~cm}, 6 \mathrm{~cm}$, and $8 \mathrm{~cm}$ cervical dilatations by VAS. It also assessed the mothers' expressions during labor. Finally, it used a Likert Scale to evaluate the mothers' satisfaction from the intervention. Part IV is a partograph sheet for the assessment of the fetal heart rate, labor progress, uterine contractions, and mother's vital signs. The researcher used this sheet to follow the mother and fetus's conditions during labor and to identify any abnormalities in the mother or fetus's conditions.

\section{Process of data collection}

The researcher visited the unit during the morning shift and stayed with the mothers until the cervical dilatation reached $8 \mathrm{~cm}$. The time spent with the mothers in the labor rooms was around 7 to 11 hours per day. Pain intensity was evaluated by asking the mothers to give scores for pain intensity that ranged between 0 and 10 . The questionnaire was filled out by researcher during her presence in the labor room with each mother. 
Results

Table 1 presents the sociodemographic and current labor characteristics of the participating mothers in the experimental and control groups. It shows that a total of 60 mothers enrolled in this study: 30 mothers in the experimental group and 30 mothers in the control group. It was found that $50 \%$ and $63.3 \%$ of the experimental and control groups, respectively, were aged between 23 and 28 years old. Regarding nationality, the majority of both groups were Saudi, $80 \%$ in the experimental group and $83.3 \%$ in the control group. Regarding levels of education, $56.7 \%$ and $63.4 \%$ of the experimental and control groups, respectively, had a university degree. Of the experimental group, $66.7 \%$ came to the hospital with intact membrane and, of the control group, $70 \%$. The mean gestational weeks of pregnancy of the mothers who came to the hospital was 39. Also, the mean duration of labor from $4 \mathrm{~cm}$ to $8 \mathrm{~cm}$ was around 7 hours in all samples. The sociodemographic and current labor variables for the mothers were the same for the experimental and control groups, as there were no significance differences in age, nationality, education, type of membrane, gestational age, and duration of labor.

Table 2 shows the results of the pain intensity assessments of the experimental and control groups. The mean pain intensity in both groups pre intervention at $4 \mathrm{~cm}$ was 1.5 , which was considered mild pain. At $6 \mathrm{~cm}$ and $8 \mathrm{~cm}$ dilatation in both groups, it was around 2.5 and 2.9, respectively, which was considered severe pain. No significant difference was observed between the two groups in pain intensity before intervention $(\mathrm{p}>0.05)$.
However, the mean pain intensity post interventions at $4 \mathrm{~cm}$ was 0.9 in the experimental group, which was considered mild pain, while in the control group, it was 1.7 , which was considered moderate pain. At $6 \mathrm{~cm}$, the mean pain intensity was 1.7 in the experimental group, while in the control group, it was 2.6, which was considered severe pain. At $8 \mathrm{~cm}$, the mean was 2.9 in both groups, which was considered severe pain. It is noteworthy that a significant difference was shown between the two groups after the intervention at $4 \mathrm{~cm}$ and $6 \mathrm{~cm}$ dilatation $(\mathrm{p}<0.05)$, but at $8 \mathrm{~cm}$, there was no statistically significant difference $(\mathrm{p}>0.05)$.

Table 3 illustrates the percentage of pain expressions in the experimental and control groups. Five items under the pain expressions were assessed before and after intervention. Pre intervention, at $4 \mathrm{~cm}$, moaning and groaning was the highest pain expression, with $43.3 \%$ in the experimental group and $36.6 \%$ in the control group. At $6 \mathrm{~cm}$, crying was the highest pain expression, with $63.3 \%$ in the experimental group and $53.3 \%$ in the control group. At $8 \mathrm{~cm}$, crying was the highest pain expression as well, with $80 \%$ in the experimental group and $73.3 \%$ in the control group. These results show that pain expression was different and increased when cervical dilatation has progressed. It is noteworthy that after conducting the intervention, the percentage of pain expression decreased more in the experimental group. At $4 \mathrm{~cm}$, moaning and groaning decreased $6.7 \%$ and $26.7 \%$ in the experimental and control groups, respectively. At $6 \mathrm{~cm}$ and 8 $\mathrm{cm}$ dilatation, crying decreased more in the experimental group compared with the control group.

\begin{tabular}{|c|c|c|c|c|c|c|c|c|}
\hline \multicolumn{2}{|c|}{$\begin{array}{c}\text { Sociodemographic and current labor } \\
\text { characteristics }\end{array}$} & \multicolumn{2}{|c|}{ Experimental group $\mathbf{n}=\mathbf{3 0}$} & \multicolumn{2}{|c|}{$\begin{array}{c}\text { Control group } \\
\mathbf{n}=\mathbf{3 0}\end{array}$} & \multicolumn{2}{|c|}{ Total } & \multirow{3}{*}{$\begin{array}{c}\text { *P-value } \\
0.07\end{array}$} \\
\hline & & $\mathrm{f}$ & $\%$ & $\mathrm{f}$ & $\%$ & $f$ & $\%$ & \\
\hline \multirow{3}{*}{ Mothers' age } & $\geq 22$ & 11 & 36.7 & 2 & 6.7 & 13 & 21.7 & \\
\hline & $23-28$ & 15 & 50.0 & 19 & 63.3 & 34 & 56.6 & \\
\hline & $\leq 29$ & 4 & 13.3 & 9 & 30.0 & 13 & 21.7 & \multirow{2}{*}{0.74} \\
\hline \multirow{2}{*}{ Nationality } & Saudi & 24 & 80.0 & 25 & 83.3 & 49 & 81.7 & \\
\hline & Non- Saudi & 6 & 20.0 & 5 & 16.7 & 11 & 18.3 & \multirow{2}{*}{0.60} \\
\hline \multirow[t]{2}{*}{ Education } & Secondary or less & 13 & 43.3 & 11 & 36.6 & 24 & 40.0 & \\
\hline & University degree & 17 & 56.7 & 19 & 63.4 & 36 & 60.0 & \multirow{3}{*}{0.78} \\
\hline \multirow{2}{*}{$\begin{array}{l}\text { Membrane on } \\
\text { admission }\end{array}$} & Intact & 20 & 66.7 & 21 & 70.0 & 41 & 68.3 & \\
\hline & Rupture & 10 & 33.3 & 9 & 30.0 & 19 & 31.7 & \\
\hline & & Mean & SD & Mean & SD & Mean & $\mathrm{SD}$ & \\
\hline \multicolumn{2}{|c|}{ Gestational age } & 39.4 & 0.8 & 39.2 & 1.0 & 39.3 & 0.9 & 0.29 \\
\hline \multicolumn{2}{|c|}{ Duration of labor $(4-8 \mathrm{~cm})$} & 7.2 & 1.5 & 7.8 & 1.4 & 7.5 & 1.4 & 0.69 \\
\hline
\end{tabular}

Table 1: Mothers' Sociodemographic and current labor characteristics.

\begin{tabular}{|l|c|c|c|c|}
\hline \multicolumn{2}{|c|}{ Pain intensity } & Experimental group; Mean \pm SD & Control group; Mean \pm SD & P - value \\
\hline \multirow{3}{*}{ Pre intervention } & $4 \mathrm{~cm}$ & $1.5 \pm 0.5$ & $1.5 \pm 0.5$ & 1.00 \\
\cline { 2 - 5 } & $6 \mathrm{~cm}$ & $2.4 \pm 0.5$ & $2.5 \pm 0.5$ & 0.63 \\
\cline { 2 - 5 } & $8 \mathrm{~cm}$ & $2.9 \pm 0.1$ & $2.9 \pm 0.1$ & 1.00 \\
\hline \multirow{3}{*}{ Post intervention } & $4 \mathrm{~cm}$ & $0.9 \pm 0.8$ & $2.6 \pm 0.4$ & 0.00 \\
\cline { 2 - 5 } & $6 \mathrm{~cm}$ & $1.7 \pm 0.4$ & $2.9 \pm 0.1$ & 0.00 \\
\cline { 2 - 5 } & $8 \mathrm{~cm}$ & $2.9 \pm 0.2$ & 0.56 \\
\hline
\end{tabular}

Table 2: Pain intensity between experimental and control group. 


\begin{tabular}{|c|c|c|c|c|c|c|}
\hline \multirow{2}{*}{ Groups } & \multicolumn{6}{|c|}{ Pre intervention $\mathbf{f}(\%)$} \\
\hline & & crying & screaming & Compress and squeeze & Moan and groan & Change position \\
\hline \multirow{2}{*}{$4 \mathrm{~cm}$} & Experimental & $9(30)$ & $2(6.7)$ & 0 & $13(43.3)$ & 0 \\
\hline & Control group & $10(33.3)$ & $6(20)$ & 0 & $11(36.6)$ & $1(3.3)$ \\
\hline \multirow{2}{*}{$6 \mathrm{~cm}$} & Experimental & $19(63.3)$ & $10(33.3)$ & 0 & $9(30)$ & $1(3.3)$ \\
\hline & Control group & $16(53.3)$ & $12(40)$ & $2(6.7)$ & $10(33.3)$ & $2(6.7)$ \\
\hline \multirow{3}{*}{$8 \mathrm{~cm}$} & Experimental & $24(80)$ & $17(56.7)$ & $10(33.3)$ & $5(16.7)$ & $8(26.7)$ \\
\hline & Control group & $22(73.3)$ & $22(73.3)$ & $8(26.7)$ & $5(16.7)$ & $13(43.3)$ \\
\hline & \multicolumn{6}{|c|}{ Post intervention $\mathrm{f}(\%)$} \\
\hline \multirow{2}{*}{$4 \mathrm{~cm}$} & Experimental & $2(6.7)$ & 0 & 0 & $2(6.7)$ & 0 \\
\hline & Control group & $7(23.3)$ & $4(13.3)$ & 0 & $8(26.7)$ & 0 \\
\hline \multirow{2}{*}{$6 \mathrm{~cm}$} & Experimental & $9(30)$ & $6(20)$ & 0 & $5(16.7)$ & 0 \\
\hline & Control group & $14(46.6)$ & $9(30)$ & $1(3.3)$ & $8(26.7)$ & 0 \\
\hline \multirow{2}{*}{$8 \mathrm{~cm}$} & Experimental & $14(46.6)$ & $9(30)$ & $7(23.3)$ & $2(6.7)$ & $5(16.7)$ \\
\hline & Control group & $22(73.3)$ & $18(60)$ & $8(26.7)$ & $4(13.3)$ & $11(36.6)$ \\
\hline
\end{tabular}

Table 3: Pain expressions between experimental and control group.

\begin{tabular}{|c|c|c|c|}
\hline Mothers' satisfaction & Experimental group Mean \pm SD & Control group Mean \pm SD & P- value \\
\hline $4 \mathrm{~cm}$ & $3.0 \pm 0.0$ & $2.9 \pm 0.2$ & 0.16 \\
\hline $6 \mathrm{~cm}$ & $2.9 \pm 0.2$ & $2.4 \pm 0.6$ & 0.00 \\
\hline $8 \mathrm{~cm}$ & $2.4 \pm 0.5$ & $1.4 \pm 0.5$ & 0.00 \\
\hline
\end{tabular}

Table 4: Mothers' satisfaction between experimental and control group.

Table 4 compares the mean mothers' satisfaction between the experimental and control groups. At $4 \mathrm{~cm}$, the mothers' satisfaction was 3.0 and 2.9 in the experimental and control groups, respectively. Moreover, at $6 \mathrm{~cm}$, the mothers' satisfaction was 2.9 in the experimental group and 2.4 in the control group. At $8 \mathrm{~cm}$, the mothers' satisfaction was 2.4 in the experimental group compared with only 1.4 in the control group. The results showed a significant difference between the two groups at $6 \mathrm{~cm}$ and $8 \mathrm{~cm}$ dilatation $(\mathrm{p}<0.05$.). At $4 \mathrm{~cm}$, no statistically significant differences were shown $(\mathrm{p}>0.05)$; however, the experimental group was more satisfied in comparison with the control group. This result shows that the mothers' satisfaction decreased when the cervical dilatation had progressed.

\section{Discussion}

Sociodemographic and current labor characteristics for the mothers were the same for experimental and control groups as there were no significance difference between them.

This study found that lower back massage was effective in reducing labor pain during the first stage of labor. The pain intensity was statistically significant decreased with lower back massage at $4 \mathrm{~cm}$ and $6 \mathrm{~cm}$ cervical dilatation. The present findings support previous studies conducted in Iran that aimed to assess the effect of lower back massage on labor pain. Their results demonstrated that the pain intensity was significantly lower in primiparous mothers who received massage therapy during labor compared with the control group $[8,9]$. In contrast, a study conducted by Barreto et al. [10] in Brazil, which aimed to assess the effect of massage in reducing severity of pain during labor, clarified that pain intensity was significantly less in the experimental group than in the control group. Moreover, a recent Cochrane systematic review that included six articles involving 326 mothers showed that massage may have a significant role in reducing pain and improving the emotional experience of labor [11]. However, the findings of the present study do not support the Janssen, Shroff, and Jaspar [4] study that aimed to assess massage therapy and labor outcome. It found that massage therapy decreased pain intensity during the first stage but not with statistical significance.

It is worth noting that after lower back massage, there was a clear decrease in the percentage of all pain expression in experimental group compared with control group. In agreement with the present finding, a study conducted in Egypt found that mothers who were crying loudly during labor were quiet after three hours of applying music therapy as a non-pharmacological method [11].

The mothers' satisfaction was assessed in experimental group and control group. This finding was significant between the two groups at $6 \mathrm{~cm}$ and $8 \mathrm{~cm}$ cervical dilatation, while at $4 \mathrm{~cm}$, no significant difference was found between the groups. In addition, this study produced results that corroborate the findings of a great deal of the previous work in this field. Jones et al. [13] and Hamideh and Siavash [8] found that satisfaction was higher in the massage groups compared with the control groups. Similarly, another study presented that mothers' satisfaction after massage therapy was rated as excellent by $70 \%$ in the group and only $39 \%$ in the control group [10].

\section{Conclusion}

This study has showed that lower back massage was effective to reduce labor pain. The experimental group had significantly 
reduced labor pain at $4 \mathrm{~cm}$ and $6 \mathrm{~cm}$ cervical dilatation compared with the control group. Also, the mothers who received lower back massage were significantly more satisfied than the mothers who received routine hospital care. Therefore, these results suggest that lower back massage can be incorporated as an effective and alternative intervention in laboring mothers.

\section{Recommendation}

Based on the findings of this study the following recommendations are presented:

- $\quad$ Raising the awareness of mothers and health care providers about the alternative methods that can be used during labor through campaigns, classes, and programs.

- Assess health care professionals' knowledge, attitudes, and practices toward lower back therapy.

- Determine the barriers to applying lower back massage faced by nurses and midwives.

\section{Acknowledgments}

First and foremost, thanks a lot to the lord Allah who helped me to accomplish this research. Sincere gratitude to my research supervisors Dr. Ahlam Eidah Al-Zahrani and Dr. Jilan Ali Al Battawi for their assistance and advice. I would like to thanks the midwives as well the mothers who accepted to participate in this study in Maternity and Children's Hospital.

\section{References}

1. Othman M, Inhaled analgesia for labor pain. 2016.

2. Davidson MR, London ML, Ladewig PW. Olds' maternalnewborn nursing \& women's health across the lifespan 10th ed. Boston Pearson. 2016.

3. Roy L, Chaillet N, Belaid L, et al. Nonpharmacologic
Approaches for Pain Management During Labor Compared with Usual Care A Meta-Analysis. 2014; 122-138.

4. Janssen P, Shroff F, Jaspar P. Massage Therapy and Labor Outcomes a Randomized Controlled Trial. 2012; 15-20.

5. Khanahmadi S. Outcomes Assessment of Pain Relief Techniques Use in Labour in Order to Increase Painless Normal Delivery Rate. International Journal of Women's Health and Reproduction Sciences. 2013; 1: 1-4.

6. Ward SL, Hisley SM, Kennedy AM. Maternal-child nursing care optimizing outcomes for mothers, children, and families. Philadelphia, PA FA. Davis Company. 2016.

7. Mona M. Nursing Boost Helping the nursing students. 2016.

8. Hamideh S, Siavash M. Effects of massage therapy and presence of attendant on pain, anxiety and satisfaction during labor. 2012; 19-23.

9. Kamalifard M, Shahnazi M, Melli MS, et al. The Efficacy of Massage Therapy and Breathing Techniques on Pain Intensity and Physiological Responses to Labor Pain. Journal of Caring Sciences. 2012; 1: 73-78.

10. Barreto R, Gallo S, Santana LS, et al. Massage reduced severity of pain during labour a randomised trial. Australian Journal of Physiotherapy. 2013; 59: 109-116.

11. Smith C, Levett K, Collins C, et al. Massage reflexology and other manual methods for pain management in labour. Cochrane Database of Systematic Reviews. 2012; 15: CD009290.

12. Salem SG. The effect of music on pain during the first stage of labor in Egypt. 2004; 1: 64-69.

13. Jones L, Othman M, Dowswell T, et al. Pain management for women in labour: an overview of systematic reviews. The Cochrane Database of Systematic Reviews. 2012; 3: CD009234.

(C) 2018 Iskandar RS, et al. This article is distributed under the terms of the Creative Commons Attribution 4.0 International License 